\title{
Impact of capillary invasion on the prognosis of gastric adenocarcinoma patients: A retrospective cohort study
}

\author{
Lian Xue ${ }^{1,2, *}$, Xiao-Long Chen ${ }^{1,2, *}$, Pan-Pan Lin ${ }^{4}$, Yuan-Wei $\mathrm{Xu}^{4}$, Wei-Han Zhang ${ }^{1,2}$, \\ Kai Liu ${ }^{1,2}$, Xin-Zu Chen ${ }^{1,2}$, Kun Yang ${ }^{1,2}$, Bo Zhang ${ }^{1}$, Zhi-Xin Chen ${ }^{1}$, Jia-Ping Chen ${ }^{1}$, \\ Zong-Guang Zhou ${ }^{1,3}$, Jian-Kun $\mathrm{Hu}^{1,2}$ \\ ${ }^{1}$ Department of Gastrointestinal Surgery, West China Hospital, Sichuan University, China \\ ${ }^{2}$ Laboratory of Gastric Cancer, State Key Laboratory of Biotherapy/Collaborative Innovation Center of Biotherapy and Cancer \\ Center, West China Hospital, Sichuan University, China \\ ${ }^{3}$ Laboratory of Digestive Surgery, State Key Laboratory of Biotherapy/Collaborative Innovation Center of Biotherapy and \\ Cancer Center West China Hospital, Sichuan University, China \\ ${ }^{4}$ West China School of Medicine, Sichuan University, China \\ *These authors contributed equally to this work
}

Correspondence to: Jian-Kun Hu, e-mail: hujkwch@126.com

Keywords: gastric adenocarcinoma, capillary invasion, prognosis, nomogram

Received: January 29, 2016

Accepted: April 11, 2016

Published: April 29, 2016

\section{ABSTRACT}

Capillary invasion (CI) has been found to play an important role in metastasis and recurrence of gastric adenocarcinoma (GAC). However, the prognostic significance of CI is still controversial. From January 2005 to December 2011, 1398 patients with GAC who underwent gastrectomy were retrospectively enrolled and divided into $\mathrm{CI}(+)$ and $\mathrm{CI}(-)$ groups. Clinicopathological features and survival outcomes were compared between these groups. In our study, $227(16.2 \%)$ patients were $\mathrm{CI}(+)$. Patients with $\mathrm{CI}(+)$ had significantly more advanced tumors and worse prognosis than those with CI $(-)(p<0.001)$. CI was demonstrated as an independent prognostic factor $(p=0.023)$ in patients with GAC. When stratified by TNM stage, the prognosis of CI $(+)$ group in stage III was remarkably worse than CI $(-)$ group $(p=0.006)$, while the differences were not significant in stage I-II and stage IV (both $p>0.05$ ). The nomograms indicated that $\mathrm{CI}$ was part of the individual prognostic prediction system. The predictive accuracy of $\mathrm{CI}$ and other characteristics was better than TNM alone $(p<0.001)$. Our finding suggested that $\mathrm{CI}$ was an independent prognostic factor in patients with GAC, and the nomogram based on $\mathrm{CI}$ and other clinicopathological factors was a valuable and accurate tool in individual prognostic prediction.

\section{INTRODUCTION}

Gastric adenocarcinoma (GAC) is one of the most common malignant cancers in the world, especially in East Asian countries like China, Korea and Japan [1]. Although prognosis of patients with GAC has been improved by early detection, chemoradiotherapy and radical lymphadenectomy, the mortality of GAC is still high, which mainly caused by recurrence and metastasis $[2,3]$. Additionally, even among patients with the same TNM stage, the long-term prognosis might be different. Therefore, it's necessary to explore new factors besides TNM stage to accurately predict prognosis in patients with GAC.
Capillary invasion (CI) is defined as lymphatic invasion and/or venous invasion according to Japanese classification of gastric carcinoma [4]. With tumor progression, tumor cells can invade blood vessels and lymphatic vessels nearby. Some studies had found that lymphatic vessels and blood vessels may help tumor metastasis and recurrence $[5,6]$. CI had been regarded as an adverse prognostic factor in some tumors like esophageal squamous cell carcinoma, lung tumor and breast cancer [7-9]. Although there were several studies on the CI in gastric cancer, the prognostic significance of CI hadn't been fully verified and needs further demonstration [10-13].The aim of this study was to find out the prognostic significance of CI in patients with GAC. 


\section{RESULTS}

\section{The relationship between $\mathrm{CI}$ and clinicopathological features}

There were 1398 patients in our study with 227 $(16.2 \%)$ patients in $\mathrm{CI}(+)$ group and $1171(83.8 \%)$ patients in CI (-) group. Of all the 1398 patients, 422 (30.2\%) were women while $976(69.8 \%)$ were men. The average age was 57.1years, ranging from 19 to 86 years.

Comparison of clinicopathological characteristics between $\mathrm{CI}(+)$ and $\mathrm{CI}(-)$ groups were shown in Table 1. Patients with CI $(+)$ had significantly more tumors with UML location $(p=0.020)$, poorly/undifferentiated differentiation grade $(p<0.001)$, larger tumor size $(p<0.001)$, more advanced macroscopic type $(p<0.001)$ and TNM stage $(p<0.001)$ than those with CI $(-)$. On the other hand, the relationship between $\mathrm{CI}(+)$ and age $(p=0.451)$, gender $(p=0.934)$ was not found. To identify the independent risk factors for CI, multivariate analyses were performed in our study (Table 2). By logistic regression analysis, we found that CI was significantly correlated to differentiation grade $(p=0.009)$ and $\mathrm{pN}$ stage $(p<0.001)$.

Because of the different constituent ratio of TNM stage in $\mathrm{CI}(+)$ and $\mathrm{CI}(-)$ groups which made some biases to compare the prognosis between these two groups directly, we then conducted the subgroup analyses according to different TNM stages: stage I-II $(n=662,47.4 \%)$, stage III $(n=655,46.9 \%)$ and stage IV $(n=81,5.7 \%)$. The rates of $\mathrm{CI}(+)$ were $8.8 \%, 22.0 \%$ and $30.9 \%$ in TNM I-II, III and IV subpopulation respectively. In the subgroup of TNM stage I-II, we found that there were more tumors with poorly differentiation grade $(p=0.026)$, more advanced $\mathrm{pT}$ stage $(p<0.001)$ and $\mathrm{pN}$ stage $(p=0.013)$ in $\mathrm{CI}(+)$ group than those in CI (-) group (Table 3 ). With regard to TNM stage III subgroup, the results demonstrated that there were more patients with $\mathrm{N} 2$ and $\mathrm{N} 3$ stage $(p<0.001)$ tumors in CI $(+)$ group than those in CI (-) group. However, in TNM IV subgroup, there were no significant differences between patients with $\mathrm{CI}(+)$ and $\mathrm{CI}(-)$.

\section{Prognostic significance of CI}

Finally, 1277 (91.3\%) patients with follow-up data were included in the survival analysis. The median survival time of patients with CI $(+)$ or CI $(-)$ was 46.4 and 96.0 months respectively. Three-year survival rates were $55.4 \%$ and $74.4 \%$ in $\mathrm{CI}(+)$ and $\mathrm{CI}(-)$ respectively. In univariate analysis by Kaplan-Meier curve (Table 4$)$, age $(p<0.001)$, longitudinal location $(p<0.001)$, differentiation grade $(p<0.001)$, macroscopic type $(p<0.001)$, tumor size $(p<0.001)$, capillary invasion $(p<0.001)$, T stage $(p<0.001)$, N stage $(p<0.001)$, M stage $(p<0.001)$ and TNM stage $(p<0.001)$ were closely associated with overall survival of gastric adenocarcinoma patients. Patients with CI $(+)$ had significant worse prognosis than those with CI $(-)$ in
Kaplan-Meier analysis ( $p<0.001$, Figure 1). Additionally, we performed multivariate analysis with Cox regression to further evaluate the prognostic significance of CI and other clinicopathological factors (Table 4), and we found that $\mathrm{CI}(p=0.023, \mathrm{HR}=1.270,95 \%$ confidence interval [1.034-1.560]) was an independent prognostic factor, as well as other clinicopathological factors like age $(p=0.002)$, tumor size $(p<0.001)$ and TNM stage $(p<0.001)$.

Survival analyses were calculated among these different subgroups respectively. The median survival time was 117.0 months and 116.0 months in stage I-II, 51.3 months and 33.8 months in stage III , 20.9 months and 24.5 months in stage IV in $\mathrm{CI}(-)$ and $\mathrm{CI}(+)$ groups respectively. The 3 -year survival rates were $89.6 \%$ and $88.9 \%$ in stage I-II, $60.3 \%$ and $46.5 \%$ in stage III, $34.7 \%$ and $26.1 \%$ in stage IV in CI $(-)$ and CI $(+)$ groups respectively. The results demonstrated that the prognosis of $\mathrm{CI}(+)$ group in stage III ( $p=0.006$, Figure 2$)$ was significantly worse than that of CI (-) group, while in stage I-II ( $p=0.556$, Figure 3$)$ and stage IV ( $p=0.904$, Figure 4$)$, the difference wasn't remarkable.

\section{Nomogram based on CI}

We also used nomogram to predict 3-year overall survival rate of individual patients. Age, tumor size, TNM stage and CI ( $p=0.015$, hazard ratio $1.292,95 \%$ confidence interval: $1.052,1.587)$ were selected in the nomogram (Figure 5). The nomograms indicated that CI was part of the individual prognostic prediction system. The results of the nomograms were similar to those of aforementioned multivariate analyses. The calibration curves of nomograms showed that the predictive probability of 3-year survival was very closely to the actual 3-year survival (Figure 6).

Subsequently, we compared the predictive accuracy of prognosis between the nomogram and TNM staging system in the study. The $\mathrm{C}$-indexes of nomograms were 0.718 ( $95 \%$ CI 0.696 0.740), compared with 0.689 (95\% CI 0.669 , 0.709 ) of TNM staging system. The differences between nomograms and TNM staging system were significant $(p<0.001)$.

\section{DISCUSSION}

CI included lymphatic invasion and/or venous invasion according to Japanese classification of gastric carcinoma [4]. Many studies had discussed the prognostic significance of lymphatic vessel invasion and blood vessel invasion respectively [9-11], however, the studies which combined these two factors together to explore the prognostic significance in GAC were few [12]. In this retrospective study, we tried to find out the prognostic significance of CI in GAC.

The presence of CI in gastric cancer was reported from $5.4 \%$ to $86 \%$ [10-16]. This could be due to the different populations included in different studies and different 
Table 1: Comparison of clinicopathological features between capillary invasion (CI) positive and negative group

\begin{tabular}{|c|c|c|c|c|}
\hline & \multirow{2}{*}{ Categories } & CI $(+)$ & CI (-) & \multirow{2}{*}{$P$ value } \\
\hline & & $n=227(\%)$ & $n=1171(\%)$ & \\
\hline \multirow[t]{2}{*}{ Age } & $<60$ years & $121(53.3)$ & $656(56.0)$ & 0.451 \\
\hline & $\geq 60$ years & $106(46.7)$ & $515(44.0)$ & \\
\hline \multirow[t]{2}{*}{ Gender } & Male & $159(70.0)$ & $817(69.8)$ & 0.934 \\
\hline & Female & $68(30.0)$ & $354(30.2)$ & \\
\hline \multirow[t]{4}{*}{ Longitudinal location } & $\mathrm{U}$ & $53(23.3)$ & $285(24.3)$ & 0.020 \\
\hline & M & $53(23.3)$ & $200(17.1)$ & \\
\hline & $\mathrm{L}$ & $114(50.2)$ & $671(57.3)$ & \\
\hline & UML & $7(3.1)$ & $15(1.3)$ & \\
\hline \multirow[t]{2}{*}{ Differentiation grade } & Well/Moderately & $21(9.3)$ & $270(23.1)$ & $<0.001$ \\
\hline & Poorly/undifferentiated & $206(90.7)$ & $901(76.9)$ & \\
\hline \multirow[t]{5}{*}{ Macroscopic type } & Type 0 & $11(4.8)$ & $202(17.3)$ & $<0.001$ \\
\hline & Type 1 & $9(4.0)$ & $47(4.0)$ & \\
\hline & Type 2 & $115(50.7)$ & $546(46.6)$ & \\
\hline & Type 3 & $75(33.0)$ & $321(27.4)$ & \\
\hline & Type 4 & $17(7.5)$ & $55(4.7)$ & \\
\hline \multirow[t]{3}{*}{ Tumor size $(\mathrm{cm})$} & Mean \pm SD & $5.6 \pm 3.2$ & $4.7 \pm 2.6$ & $<0.001$ \\
\hline & $<5 \mathrm{~cm}$ & $92(40.5)$ & $630(53.8)$ & \\
\hline & $\geq 5 \mathrm{~cm}$ & $135(59.5)$ & $541(46.2)$ & \\
\hline \multirow[t]{4}{*}{ T stage } & $\mathrm{T} 1$ & $17(7.5)$ & $312(26.6)$ & $<0.001$ \\
\hline & $\mathrm{T} 2$ & $34(15.0)$ & $165(14.1)$ & \\
\hline & $\mathrm{T} 3$ & $17(7.5)$ & $101(8.6)$ & \\
\hline & $\mathrm{T} 4$ & $159(70.0)$ & $593(50.6)$ & \\
\hline \multirow[t]{4}{*}{$\mathrm{N}$ stage } & No & $34(15.0)$ & $461(39.4)$ & $<0.001$ \\
\hline & N1 & $29(12.8)$ & $204(17.4)$ & \\
\hline & $\mathrm{N} 2$ & $33(14.5)$ & $191(16.3)$ & \\
\hline & N3 & $131(57.7)$ & 315 (26.9) & \\
\hline \multirow[t]{2}{*}{ M stage } & M0 & $202(89.0)$ & $1115(95.2)$ & $<0.001$ \\
\hline & M1 & $25(11.0)$ & $56(4.8)$ & \\
\hline \multirow[t]{4}{*}{ TNM stage } & I & $26(11.5)$ & $376(32.1)$ & $<0.001$ \\
\hline & II & $32(14.1)$ & $228(19.5)$ & \\
\hline & III & $144(63.4)$ & $511(43.6)$ & \\
\hline & IV & $25(11.0)$ & $56(4.8)$ & \\
\hline \multirow[t]{2}{*}{ Adjuvant therapy } & Yes & $104(45.8)$ & $504(43.0)$ & 0.440 \\
\hline & No & $123(54.2)$ & $667(57.0)$ & \\
\hline
\end{tabular}

Abbreviations: SD: standard deviation, U: upper, M: middle, L: lower. 
Table 2: Multivariate analysis of risk factors for capillary invasion (CI)

\begin{tabular}{|c|c|c|c|}
\hline Factors & Adjusted OR & $95 \%$ CI & $P$ value \\
\hline Age & & & 0.196 \\
\hline Gender & & & 0.786 \\
\hline Longitudinal location & & & 0.954 \\
\hline Differentiation grade & 1.915 & $1.176-3.116$ & 0.009 \\
\hline Macroscopic type & & & 0.352 \\
\hline Tumor size $(\mathrm{cm})$ & & & 0.969 \\
\hline T stage & & & 0.299 \\
\hline $\mathrm{N}$ stage & 1.690 & $1.483-1.925$ & $<0.001$ \\
\hline M stage & & & 0.333 \\
\hline
\end{tabular}

Abbreviations: SD: standard deviation.

Table 3: Clinicopathological features of capillary invasion (CI) negative and positive groups stratified by TNM stage

\begin{tabular}{|c|c|c|c|c|c|c|c|c|c|c|}
\hline & & \multicolumn{3}{|c|}{ Stage I-II $(n=662,47.4 \%)$} & & & & \multicolumn{3}{|c|}{ Stage IV $(n=81,5.7 \%)$} \\
\hline & & $\begin{array}{l}\text { Negative } \\
(\%)\end{array}$ & $\begin{array}{c}\text { Positive } \\
\text { (\%) }\end{array}$ & \multirow{2}{*}{$P$ value } & $\begin{array}{c}\text { Negative } \\
(\%)\end{array}$ & $\begin{array}{c}\text { Positive } \\
(\%)\end{array}$ & \multirow{2}{*}{$P$ value } & $\begin{array}{c}\text { Negative } \\
(\%)\end{array}$ & $\begin{array}{c}\text { Positive } \\
\text { (\%) }\end{array}$ & \multirow{2}{*}{$P$ value } \\
\hline & & $(n=604)$ & $(n=58)$ & & $(n=511)$ & $(n=144)$ & & $(n=56)$ & $(n=25)$ & \\
\hline \multirow[t]{3}{*}{$\begin{array}{l}\text { Age } \\
\text { (year) }\end{array}$} & $\begin{array}{l}\text { Mean } \pm \\
\text { SD }\end{array}$ & $56.8 \pm 11.9$ & $57.2 \pm 12.9$ & 0.807 & $57.0 \pm 11.3$ & $58.4 \pm 11.7$ & 0.201 & $57.0 \pm 12.5$ & $56.8 \pm 11.1$ & 0.936 \\
\hline & $<60$ & $338(56)$ & $31(53.4)$ & 0.713 & $289(56.6)$ & $74(51.4)$ & 0.271 & $29(51.8)$ & $16(64.0)$ & 0.307 \\
\hline & $\geq 60$ & $266(44)$ & $27(46.6)$ & & $222(43.4)$ & $70(48.6)$ & & $27(48.2)$ & $9(36.0)$ & \\
\hline \multirow[t]{2}{*}{ Gender } & Male & $424(70.2)$ & $34(58.6)$ & 0.068 & $357(69.9)$ & $110(76.4)$ & 0.126 & $36(64.3)$ & $15(60.0)$ & 0.712 \\
\hline & Female & $180(29.8)$ & $24(41.4)$ & & $154(30.1)$ & $34(23.6)$ & & $20(35.7)$ & $10(40.0)$ & \\
\hline $\begin{array}{l}\text { Longitu- } \\
\text { dinal }\end{array}$ & $\mathrm{U}$ & $110(18.2)$ & $15(25.9)$ & 0.201 & $158(30.9)$ & $34(23.6)$ & 0.128 & $17(30.4)$ & $4(16.0)$ & 0.115 \\
\hline \multirow[t]{3}{*}{ location } & $M$ & $96(15.9)$ & $7(12.1)$ & & 95 (18.6) & $36(25)$ & & $9(16.1)$ & $10(40.0)$ & \\
\hline & $\mathrm{L}$ & $396(65.6)$ & $35(60.3)$ & & $251(49.1)$ & $70(48.6)$ & & $24(42.9)$ & $9(36.0)$ & \\
\hline & UML & $2(0.3)$ & $1(1.7)$ & & $7(1.4)$ & $4(2.8)$ & & $6(10.7)$ & $2(8.0)$ & \\
\hline $\begin{array}{l}\text { Macro- } \\
\text { scopic }\end{array}$ & Type 0 & $196(32.5)$ & $8(13.8)$ & 0.067 & $6(1.2)$ & $2(1.4)$ & 0.988 & $0(0)$ & $1(4.0)$ & 0.601 \\
\hline \multirow[t]{4}{*}{ type } & Type 1 & $32(5.3)$ & $4(6.9)$ & & $11(2.2)$ & $4(2.8)$ & & $4(7.1)$ & $1(4.0)$ & \\
\hline & Type 2 & $266(44)$ & $32(55.2)$ & & 255 (49.9) & $70(48.6)$ & & $25(44.6)$ & $13(52.0)$ & \\
\hline & Type 3 & $104(17.2)$ & $13(22.4)$ & & $196(38.4)$ & $55(38.2)$ & & $21(37.5)$ & $7(28.0)$ & \\
\hline & Type 4 & $6(1)$ & $1(1.7)$ & & $43(8.4)$ & $13(9.0)$ & & $6(10.7)$ & $3(12.0)$ & \\
\hline $\begin{array}{l}\text { Differ- } \\
\text { entiation }\end{array}$ & $\begin{array}{l}\text { Well/ } \\
\text { Moder- } \\
\text { ately }\end{array}$ & $201(33.3)$ & $11(19.0)$ & 0.026 & $62(12.1)$ & $10(6.9)$ & 0.079 & $7(12.5)$ & $0(0)$ & 0.093 \\
\hline grade & Poorly & $403(66.7)$ & $47(81.0)$ & & 449 (87.9) & $134(93.1)$ & & 49 (87.5) & $25(100.0)$ & \\
\hline $\begin{array}{l}\text { Tumor } \\
\text { size }\end{array}$ & $\begin{array}{l}\text { Mean } \pm \\
\text { SD }\end{array}$ & $3.5 \pm 2.0$ & $3.9 \pm 2.3$ & 0.150 & $5.8 \pm 2.5$ & $6.0 \pm 2.9$ & 0.309 & $7.1 \pm 3.4$ & $7.2 \pm 4.5$ & 0.870 \\
\hline
\end{tabular}




\begin{tabular}{|c|c|c|c|c|c|c|c|c|c|c|}
\hline$(\mathrm{cm})$ & $<5$ & $456(75.5)$ & $43(74.1)$ & 0.819 & $162(31.7)$ & $43(29.9)$ & 0.674 & $12(21.4)$ & $6(24.0)$ & 0.797 \\
\hline & $\geq 5$ & $148(24.5)$ & $15(25.9)$ & & $349(68.3)$ & $101(70.1)$ & & 44 (78.6) & $19(76.0)$ & \\
\hline \multirow[t]{4}{*}{ pT stage } & $\mathrm{T} 1$ & $312(51.7)$ & $16(27.6)$ & $<0.001$ & $0(0)$ & $0(0)$ & 0.861 & $0(0)$ & $1(4.0)$ & 0.178 \\
\hline & $\mathrm{T} 2$ & $138(22.8)$ & $27(46.6)$ & & $27(5.3)$ & $6(4.2)$ & & $0(0)$ & $1(4.0)$ & \\
\hline & $\mathrm{T} 3$ & $58(9.6)$ & $5(8.6)$ & & $41(8.0)$ & $12(8.3)$ & & $2(3.6)$ & $0(0)$ & \\
\hline & $\mathrm{T} 4$ & $96(15.9)$ & $10(17.2)$ & & $443(86.7)$ & $126(87.5)$ & & $54(96.4)$ & $23(92.0)$ & \\
\hline \multirow[t]{4}{*}{ pN stage } & N0 & $455(75.3)$ & $33(56.9)$ & 0.013 & $4(0.8)$ & $1(0.7)$ & $<0.001$ & $2(3.6)$ & $0(0)$ & 0.547 \\
\hline & N1 & $112(18.5)$ & $19(32.8)$ & & $90(17.6)$ & $10(6.9)$ & & $2(3.6)$ & $0(0)$ & \\
\hline & N2 & $31(5.1)$ & $4(6.9)$ & & $155(30.3)$ & $25(17.4)$ & & $5(8.9)$ & $4(16.0)$ & \\
\hline & N3 & $6(1.0)$ & $2(3.4)$ & & $262(51.3)$ & $108(75.0)$ & & $47(83.9)$ & $21(84.0)$ & \\
\hline \multirow[t]{2}{*}{ M stage } & M0 & $\begin{array}{c}604 \\
(100.0)\end{array}$ & $58(100.0)$ & - & $511(100.0)$ & $144(100.0)$ & - & $0(0)$ & $0(0)$ & - \\
\hline & M1 & $0(0)$ & $0(0)$ & & $0(0)$ & $0(0)$ & & $56(100.0)$ & $25(100.0)$ & \\
\hline \multirow[t]{4}{*}{$\begin{array}{l}\text { TNM } \\
\text { stage }\end{array}$} & I & $376(62.3)$ & $26(44.8)$ & 0.009 & $0(0)$ & $0(0)$ & - & $0(0)$ & $0(0)$ & - \\
\hline & II & $228(37.7)$ & $32(55.2)$ & & $0(0)$ & $0(0)$ & & $0(0)$ & $0(0)$ & \\
\hline & III & - & - & & $511(100.0)$ & $144(100.0)$ & & $0(0)$ & $0(0)$ & \\
\hline & IV & - & - & & $0(0)$ & $0(0)$ & & $56(100.0)$ & $25(100.0)$ & \\
\hline
\end{tabular}

Table 4: Univariate and multivariate Cox analysis for prognostic factors

\begin{tabular}{|c|c|c|c|c|c|}
\hline \multirow{2}{*}{ Risk factors } & \multirow{2}{*}{ Categories } & \multirow{2}{*}{$\begin{array}{c}\text { Univariate } \\
\text { analysis } \\
P \text { value } \\
\end{array}$} & \multicolumn{3}{|c|}{ Multivariate analysis } \\
\hline & & & HR & $95 \% \mathrm{CI}$ & $P$ value \\
\hline \multirow[t]{2}{*}{ Age (years) } & $<60$ & $<0.001$ & 1.306 & $1.104-1.546$ & 0.002 \\
\hline & $\geq 60$ & & & & \\
\hline \multirow[t]{2}{*}{ Gender } & Male & 0.074 & & & 0.345 \\
\hline & Female & & & & \\
\hline \multirow[t]{4}{*}{$\begin{array}{l}\text { Longitudinal loca- } \\
\text { tion }\end{array}$} & $\mathrm{U}$ & $<0.001$ & & & 0.139 \\
\hline & $\mathrm{M}$ & & & & \\
\hline & $\mathrm{L}$ & & & & \\
\hline & UML & & & & \\
\hline \multirow[t]{2}{*}{ Differentiation grade } & $\begin{array}{l}\text { Well/Moderate } \\
\text { differentiated }\end{array}$ & $<0.001$ & & & 0.692 \\
\hline & Poor/undifferentiated & & & & \\
\hline \multirow[t]{5}{*}{ Macroscopic type } & Type 0 & $<0.001$ & & & 0.198 \\
\hline & Type 1 & & & & \\
\hline & Type 2 & & & & \\
\hline & Type 3 & & & & \\
\hline & Type 4 & & & & \\
\hline \multirow[t]{2}{*}{ Tumor size } & $<5 \mathrm{~cm}$ & $<0.001$ & 1.425 & $1.183-1.717$ & $<0.001$ \\
\hline & $\geq 5 \mathrm{~cm}$ & & & & \\
\hline \multirow[t]{2}{*}{ Capillary invasion } & Positive & $<0.001$ & 1.270 & $1.034-1.560$ & 0.023 \\
\hline & Negative & & & & \\
\hline T stage & T1 & $<0.001$ & - & - & - \\
\hline
\end{tabular}




\begin{tabular}{|l|l|l|l|l|l|}
\hline & T2 & & & & \\
\hline & T3 & & & & \\
\hline & T4 & & & & \\
\hline N stage & N0 & $<0.001$ & - & - & \\
\hline & N1 & & & & \\
\hline & N2 & & & & \\
\hline & N3 & & & & - \\
\hline M stage & M0 & $<0.001$ & - & - & \\
\hline & M1 & & & & $<0.001$ \\
\hline TNM stage & I & $<0.001$ & 1.953 & $1.745-2.185$ & \\
\hline & II & & & & \\
\hline & III & & & & \\
\hline & IV & & & & \\
\hline
\end{tabular}

methods such as retrospective studies or experimental studies by HE staining and immunohistochemical staining. We observed the presence of $\mathrm{CI}$ in gastric adenocarcinoma was $16.2 \%$ in our patients. The incidence of CI was found to increase with the progression of tumor. There was a significant positive relationship between CI and TNM stage which was similar to previous study [10]. In our study, we found that gastric adenocarcinoma patients with $\mathrm{CI}(+)$ had more poorly differentiated tumors, larger tumor size and more advanced macroscopic type and TNM stage than CI (-) group, which was similar to previous researches $[17,18]$. We concluded that CI was associated with tumor aggressiveness. And we also found that CI was significantly associated with differentiation grade and $\mathrm{pN}$ stage in multivariate analysis. One explanation to this was that when the tumor cells metastasis to the lymph nodes, it would pass through the lymphatic vessels, and the probability of lymphatic vessels invasion would increase significantly. Our results were similar to previous study and could also suggest the viewpoint that presence of CI can be an indication for a more extensive surgical resection [10]. Del Casar reported that lymphatic and blood vessels invasion was closely associated with undifferentiated histological subtype [10]. And in our study, we also found the similar

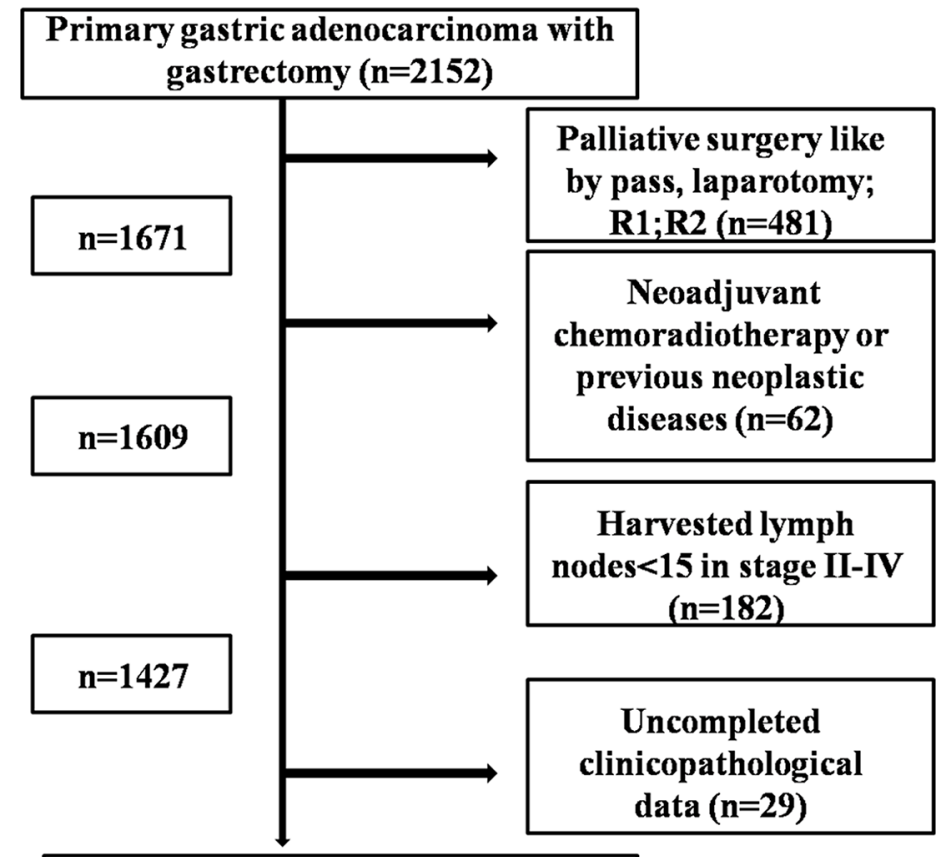

Patients in the study $(n=1398)$

Figure 1: Flow chart of the patients. 


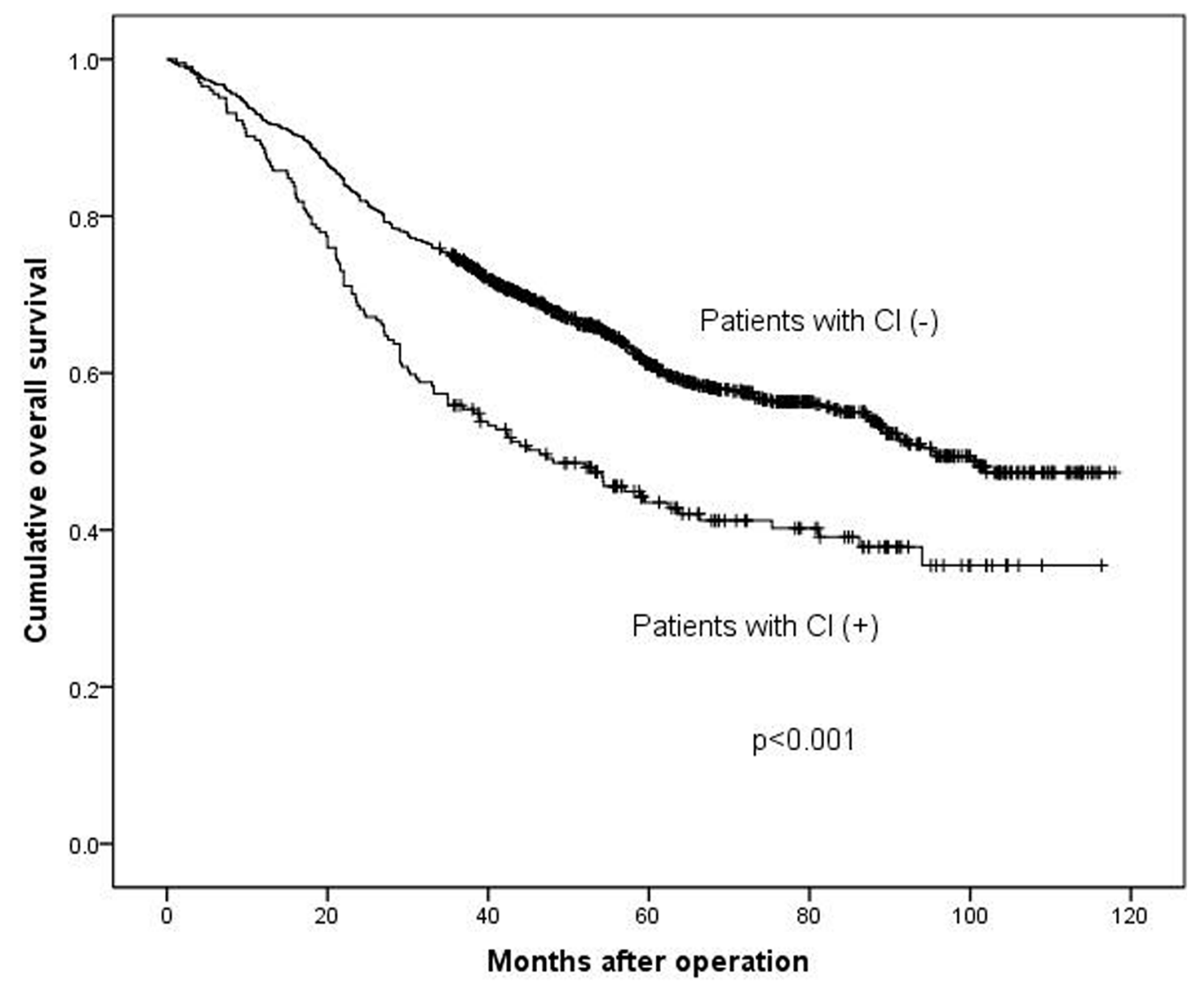

Figure 2: Survival analysis between patients with CI $(+)$ and CI $(-)$.

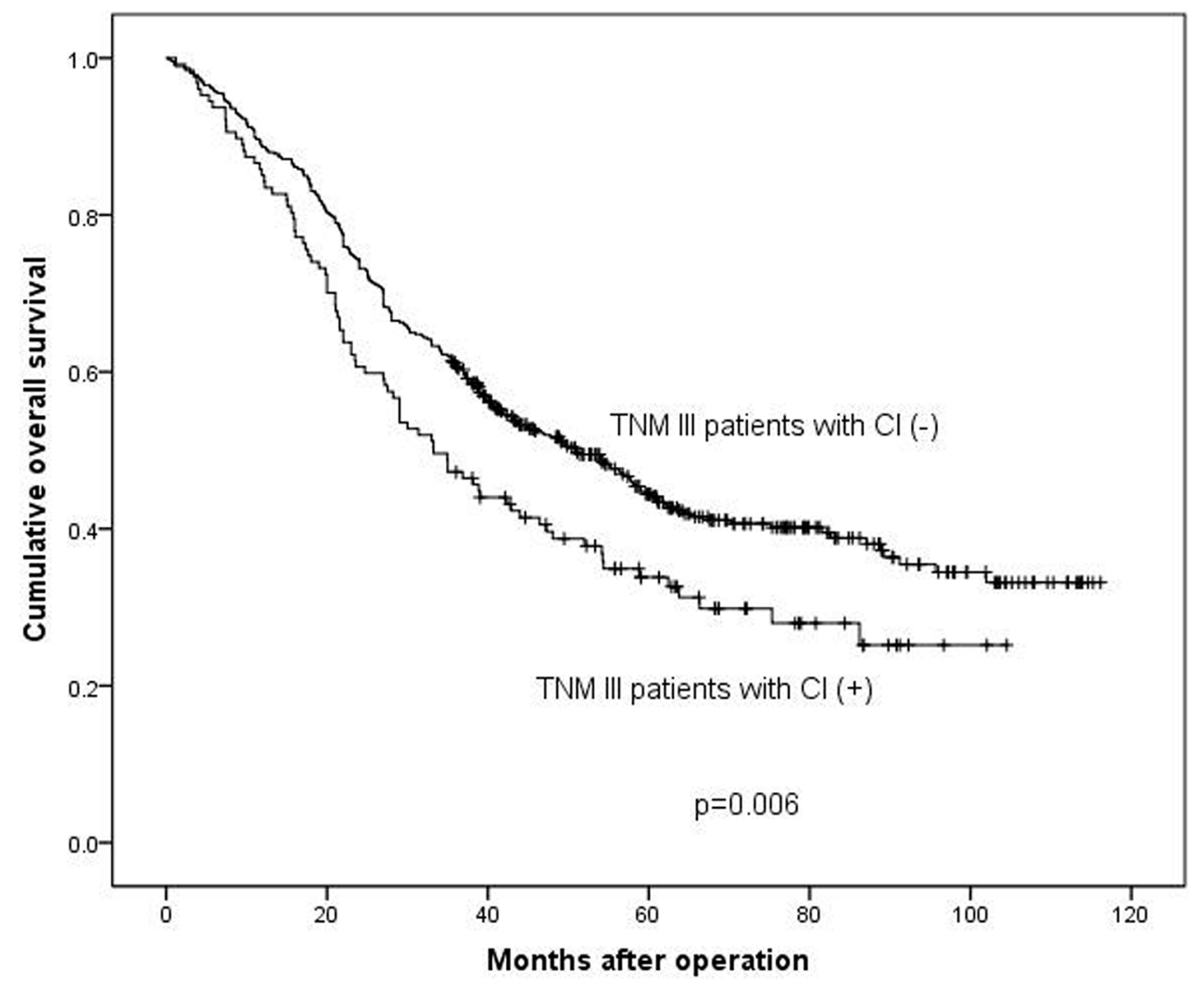

Figure 3: Survival analysis between TNM III stage patients with CI (+) and CI (-). 
results. The reason might be that tumor cells in poorly differentiated tumors tended to metastasis more easily than well differentiated tumors, which could also increase the probability of blood vessels and lymphatic vessels invasion.

Some studies reported that CI was an independent prognostic factor by multivariate survival analysis [10, 11], while other study demonstrated that CI didn't show prognostic significance as an independent prognostic factor for all patients with gastric carcinoma [19].
We found that the presence of CI was an independent prognostic factor in patients with GAC $(p=0.023)$. We also found that the patients with $\mathrm{CI}(+)$ had worse prognosis than CI $(-)$ patients $(p<0.001)$, which was consistent with previous studies $[17,20]$. The reason might be that patients with $\mathrm{CI}(+)$ had more advanced TNM stage tumors. In order to eliminate the bias caused by different constituent ratio of TNM stage in CI $(+)$ and CI (-) groups, we divided patients into three subgroups

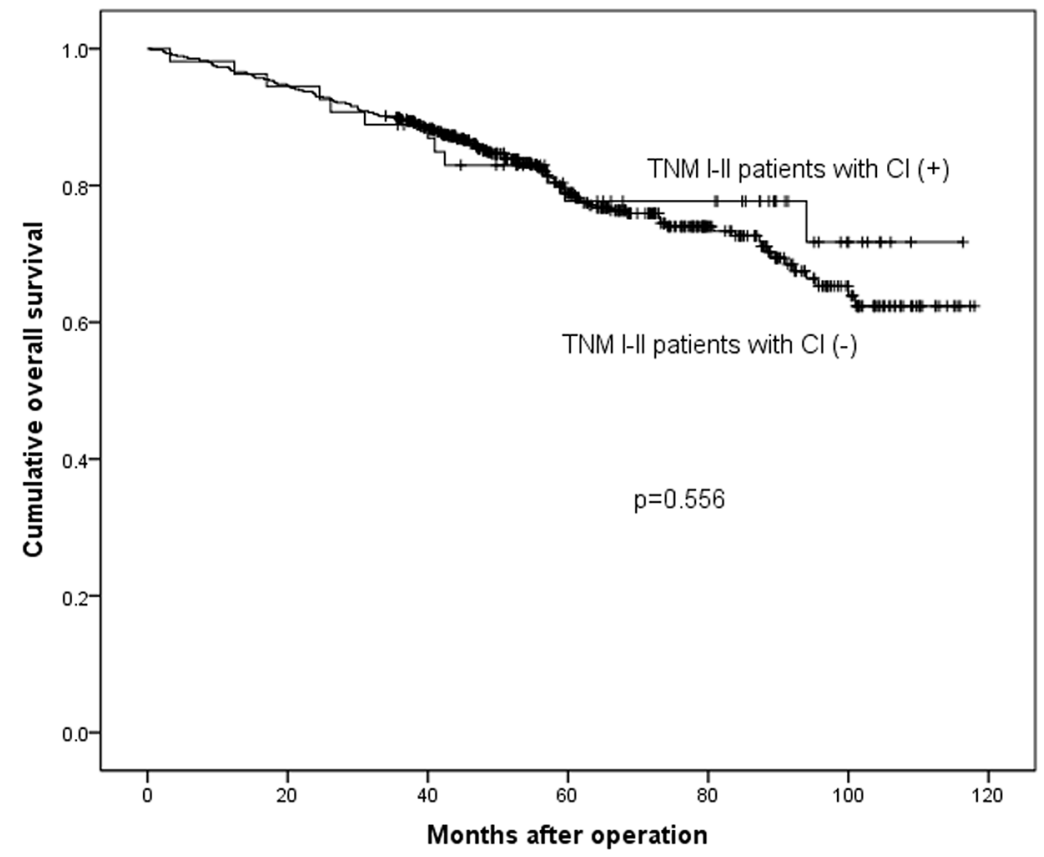

Figure 4: Survival analysis between TNM I-II stage patients with CI (+) and CI (-).

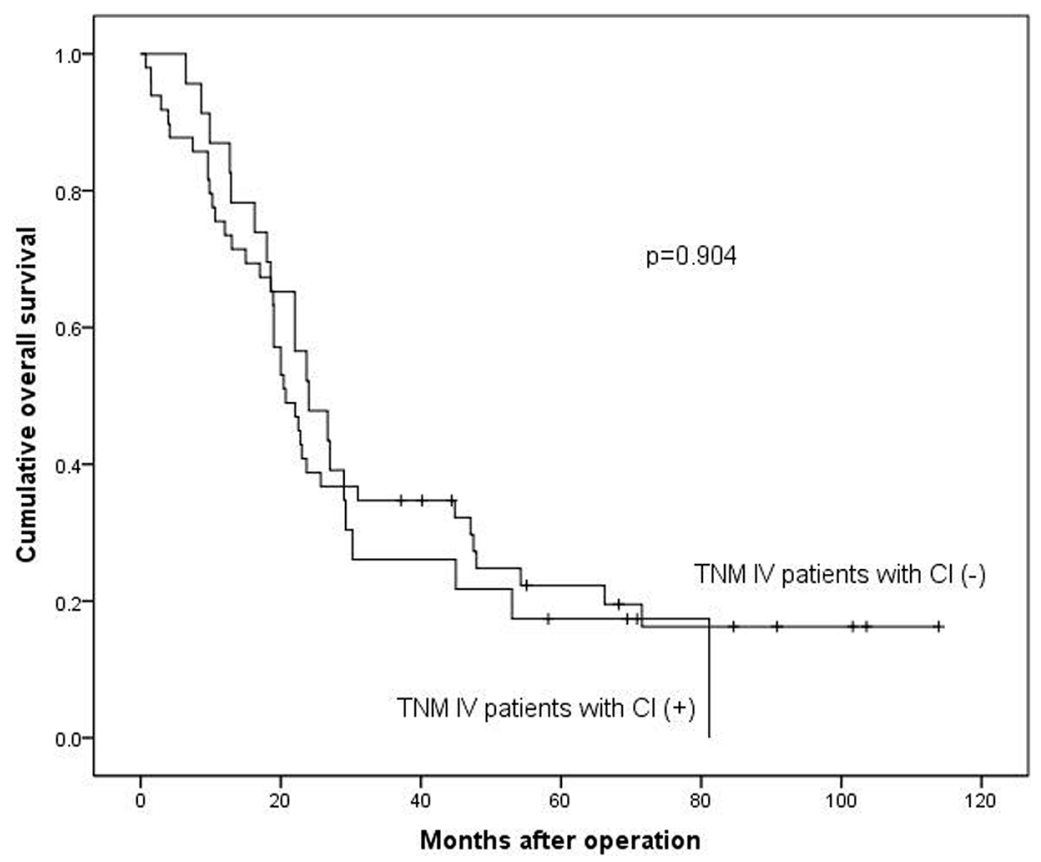

Figure 5: Survival analysis between TNM IV stage patients with CI (+) and CI (-). 
(TNM I-II subgroup, III subgroup and IV subgroup) according to their TNM stage to minimize the influence of survival outcomes by TNM stage. After the stratification, we further compared the prognosis between patients with CI $(+)$ and CI (-) in each subgroups. The prognosis didn't show significant difference between TNM I-II subgroup $(p=0.556)$ and TNM IV subgroup $(p=0.904)$. However, in TNM III stage subgroup, we found that patients with CI had significantly worse prognosis than the ones without CI $(p=0.006)$. The possible explanation might be that the prognosis of patients with TNM I-II stage is much better than patients with III or IV TNM stages, and maybe the adverse effect of CI can't be completely reflected in TNM I-II stage and the CI may not influence the prognosis of patients with TNM I-II severely. Thus the prognoses of CI (+) and CI (-) patients in TNM I-II subgroup were not significantly different. Similarly, the prognosis of patients with TNM IV stage is too worse to be influenced by CI. Thus, CI could show its adverse prognostic value only in gastric adenocarcinoma patients with TNM III stage. Although distant metastasis didn't appear in patients with TNM III stage, we still should pay attention to TNM III stage patients with CI $(+)$ for their worse prognosis than patients with $\mathrm{CI}(-)$.
Nomogram is a visualized method to predict the prognosis of individual patient on the basis of some valuable parameters. According to nomogram, the prognosis of individual patients can be predicted well. In our study, we also compared the predictive accuracy between nomogram and TNM staging system, and the results showed that nomogram with CI and other characteristics was better than TNM alone. However, we still considered TNM stage as one of the most important prognostic factors of GAC, but more importantly, other indexes like CI should be also noticed.

In this retrospective study, patients with GAC were enrolled to discuss the prognostic significance of CI. Patients with $\mathrm{CI}(+)$ had more advanced TNM stage tumors and worse prognosis than those with $\mathrm{CI}(-)$, especially in TNM III stage. And the CI turned out to be an independent prognostic factor for patients with GAC. Although TNM stage is the most important factor to predict survival of patients with GAC, other indexes like CI shouldn't be ignored neither. However, the present findings are retrospective and it's necessary to carry out prospective, randomized, controlled study to examine the prognostic value of $\mathrm{CI}$ in GAC.

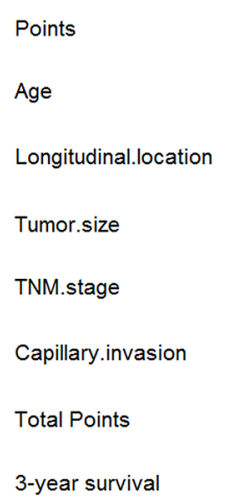

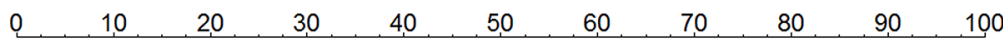

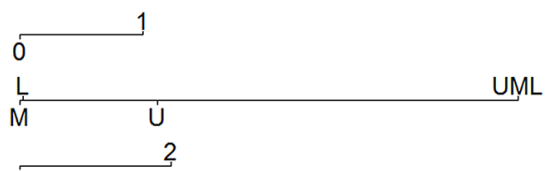

$$
1
$$
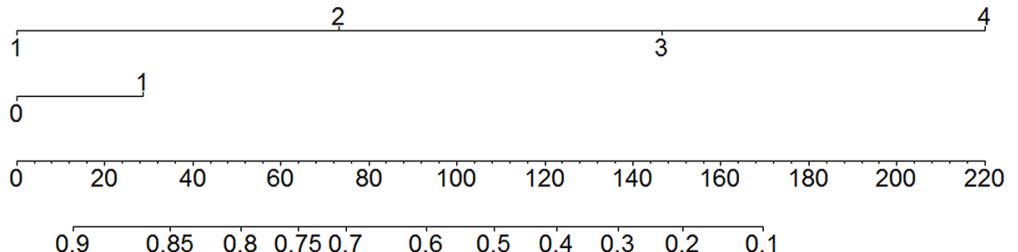

Figure 6: Nomogram for gastric adenocarcinoma patients.

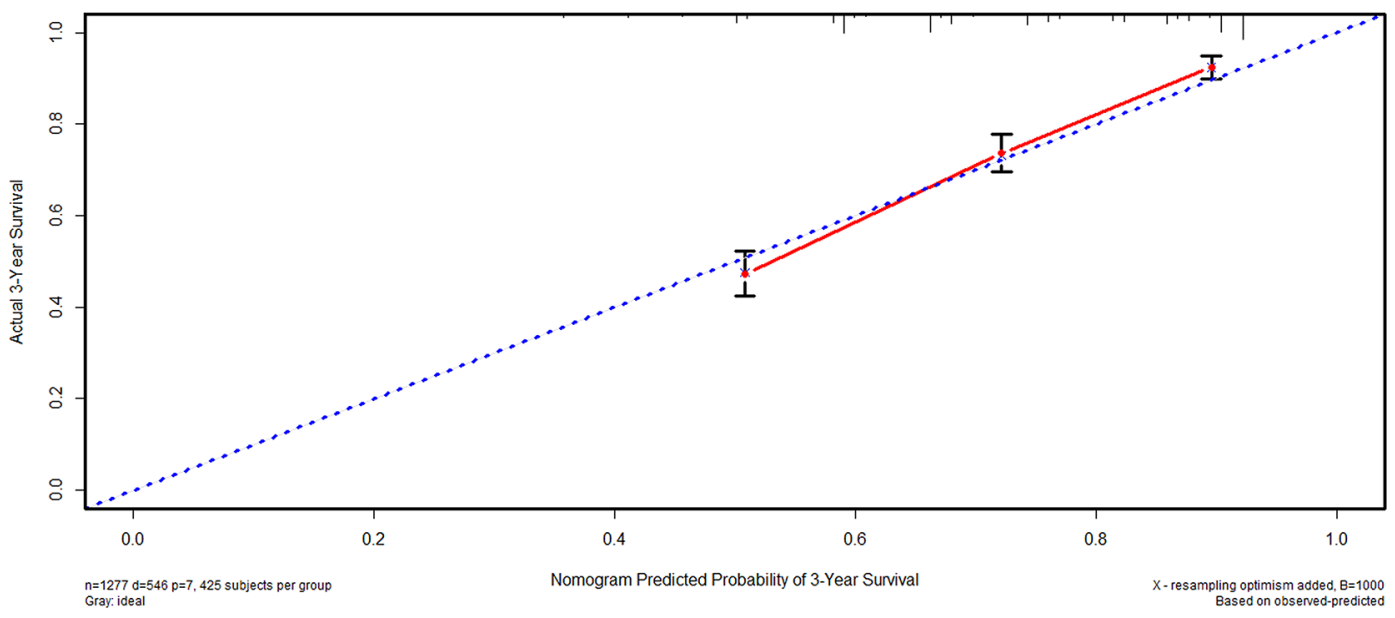

Figure 7: Calibration curve for gastric adenocarcinoma patients. 


\section{MATERIALS AND METHODS}

The West China Hospital research ethics committee approved retrospective analysis of anonymous data. Signed patient informed consent was waived per the committee approval, because it was a retrospective analysis.

\section{Patients}

In our study, we enrolled patients with GAC who underwent gastrectomy with curative intent from Department of Gastrointestinal Surgery, West China Hospital from January 2005 to December 2011. Patients with neoadjuvant chemoradiotherapy, previous neoplastic diseases and uncompleted clinicopathological data were excluded. To eliminate the impact of insufficient lymphadenectomy, we also excluded TNM stage II-IV patients with less than 15 lymph nodes harvested in surgery. Finally, there were 1398 patients in our study (Figure 7). The clinicopathological features of these patients such as tumor size, differentiation grade, macroscopic type and TNM stage which was defined according to Japanese classification of gastric carcinoma by JGCA were recorded [4]. Patients were divided according to whether they had capillary invasion: CI $(+)$ and CI (-) groups.

\section{Capillary invasion}

$\mathrm{CI}$ including lymphatic invasion and venous invasion was defined as the presence of tumor cells in the lumen of lymphatic/venous vessels, which were lined by endothelial cells. The histopathology reports of the specimens were made by experienced pathologists from West China Hospital.

\section{Follow-up}

Follow-up information was updated to January 2015. Regular outpatient visit was chosen as the main method for follow-up, while telephones and mails were selected as two main supplementary methods. The main reasons for the loss of follow-up were the changes of phone number or home address and refusal of re-examination in our hospital.

\section{Statistical analysis}

All the statistical analyses were performed with the statistical software SPSS 19.0 (SPSS $^{\circledR}$, Chicago, Illinois, USA). All continuous variables were presented as mean \pm standard deviation (SD). Unordered categorical variable and ranked data was analyzed by chi-square test and rank sum test (Mann-Whitney $U$ test), respectively. Student's $t$-test was used to analyze continuous data if homogeneity of variance and normal distribution. If not, rank sum test was used. Logistic regression was used in multivariate correlation analysis. Kaplan-Meier method and life-table method were used to calculate the cumulative survival rate. Log- rank test and Cox's proportional hazard regression model were conducted for univariate and multivariate survival analyses, respectively. Nomogram and calibration curve were performed through $\mathrm{R}$ for Windows (Version 3.2.0, R Foundation for Statistical Computing) with the package of Regression Modeling Strategies (rms), in which the variables were selected according to the model by Akaike information criterion in a stepwise algorithm. Comparisons between the nomogram and TNM staging systems were performed with the package of Harrell Miscellaneous (Hmisc) and were evaluated by the $\mathrm{C}$-index, with the meaning of that the larger the $\mathrm{C}$-index, the more accurate was the prognostic prediction. $P$ value less than 0.05 was considered as statistical significance.

\section{ACKNOWLEDGMENTS AND FUNDING}

This research was funded by this source: 1 . National Natural Science Foundation of China, No.81372344. 2. West China Hospital 1.3.5 Project. Authors thank the substantial work of Volunteer Team of Gastric Cancer Surgery (VOLTGA) based on Multidisciplinary Team (MDT) of Gastrointestinal Tumors, West China Hospital, Sichuan University, China.

\section{CONFLICTS OF INTEREST}

None.

\section{REFERENCES}

1. Jemal A, Bray F, Siegel RL, Ferlay J, Lortet-Tieulent J, Jemal A. Global cancer statistics. CA Cancer J Clin. 2015; 65:87-108.

2. Wang J, Yu JC, Kang WM, Ma ZQ. Treatment strategy for early gastric cancer. Surg Oncol. 2012; 21:119-123.

3. Dimitrios HR. Targeting gastric cancer with trastuzumab: new clinical practice and innovative developments to overcome resistance. Ann Surg Oncol. 2010; 17:14-17.

4. Japanese gastric cancer association: Japanese classification of gastric carcinoma: 3rd English version. Gastric Cancer. 2011; 14:101-112.

5. Yokota T, Ishiyama S, Saito T, Teshima S, Shimotsuma M, Yamauchi H. Treatment strategy of limited surgery in the treatment guidelines for gastric cancer in Japan. Lancet Oncol. 2003; 4:423-428.

6. Yoshida K, Yamaguchi K, Okumura N, Osada S, Takahashi T, Tanaka Y, Tanabe K, Suzuki T. The roles of surgical oncologists in the new era: minimally invasive surgery for early gastric cancer and adjuvant surgery for metastatic gastric cancer. Pathobiology. 2011; 78:343-352.

7. Brücher BL, Stein HJ, Werner M, Siewert JR. Lymphatic vessel invasion is an independent prognostic factor in patients with a primary resected tumor with esophageal squamous cell carcinoma. Cancer 2001; 92:2228-2233. 
8. Schmid K, Birner P, Gravenhorst V, End A, Geleff S. Prognostic value of lymphatic and blood vessel invasion in neuroendocrine tumors of the lung. Am J Surg Pathol. 2005; 29:324-328

9. Ito M, Moriya T, Ishida T, Usami S, Kasajima A, Sasano H, OhuchiN. Significance of pathological evaluation for lymphatic vessel invasion in invasive breast cancer. Breast Cancer. 2007; 14:381-387.

10. Del Casar JM, Corte MD, Alvarez A, García I, Bongera M, González LO, García-Muñiz JL, Allende MT, Astudillo A, Vizoso FJ. Lymphatic and/or blood vessel invasion in gastric cancer: relationship with clinicopathological parameters, biological factors and prognostic significance. J Cancer Res Clin Oncol. 2008; 134:153-161.

11. Dicken BJ, Graham K, Hamilton SM, Andrews S, Lai R, Listgarten J, Jhangri GS, Saunders LD, Damaraju S, Cass C. Lymphovascular invasion is associated with poor survival in gastric cancer: an application of gene-expression and tissue array techniques. Ann Surg. 2006; 243:64-73.

12. Jong-Han Kim, Sung-Soo Park, Seong-Heum Park, Seung-Joo Kim, Young-Jae Mok, Chong-Suk Kim, Ju-Han Lee, Young-Sik Kim. Clinical significance of immunohistochemically-identified lymphatic and/or blood vessel tumor invasion in gastric cancer. Journal of Surgical Research. 2010; 162:177-183.

13. Kunisaki C, Makino H, Kimura J, Takagawa R, Kosaka T, Ono HA, Akiyama H, Fukushima T, Nagahori Y, Takahashi M. Impact of lymphovascular invasion in patients with stage I gastric cancer. Surgery. 2010; 147:204-211.

14. Yonemura Y, Endou Y, Tabachi K, Kawamura T, Yun HY, Kameya T, Hayashi I, Bandou E, Sasaki T, Miura M. Evaluation of lymphatic invasion in primary gastric cancer by a new monoclonal antibody, D2-40. Hum Pathol. 2006; 37:1193-1199.
15. Arigami T, Natsugoe S, Uenosono Y, Arima H, Mataki Y, Ehi K, Yanagida S, Ishigami S, Hokita S, Aikou T. Lymphatic invasion using D2-40 monoclonal antibody and its relationship to lymph node micrometastasis in $\mathrm{pN} 0$ gastric cancer. Br J Cancer. 2005; 93:688-693.

16. Hyung WJ, Lee JH, Choi SH, Min JS, Noh SH. Prognostic impact of lymphatic and/or blood vessel invasion in patients with node-negative advanced gastric cancer. Ann Surg Oncol. 2002; 9:562-567.

17. Enyi Liu, Meizuo Zhong, Fang Xu, Wei Liu, Jin Huang,Shan Zeng, Jingchen Lu, Bin Li, Jianhuang Li, Hairong Jiang. Impact of Lymphatic Vessel Invasion on Survival in Curative Resected Gastric Cancer. J Gastrointest Surg. 2011; 15:1526-1531.

18. Chun-Yan Du, Jing-Gui Chen, Ye Zhou, Guang-Fa Zhao, Hong Fu, Xue-Ke Zhou, Ying-Qiang Shi. Impact of lymphatic and/or blood vessel invasion in stage II gastric cancer. World J Gastroenterol. 2012; 21;18:3610-3616.

19. Yokota T, Kunii Y, Teshima S, Yamada Y, Saito T, Takahashi M, Kikuchi S, Yamauchi H. Significant prognostic factors in patients with early gastric cancer. Int Surg. 2000; 85:286.

20. Ichikawa D, Kubota T, Kikuchi S, Fujiwara H, Konishi H, TsujiuraM, Ikoma H, Nakanishi M, Okamoto K, Sakakura C, Ochiai T,Kokuba Y, Otsuji E. Prognostic impact of lymphatic invasion inpatients with node-negative gastric cancer. J Surg Oncol. 2009; 100:111-114. 